\title{
CONTRIBUIÇÕES DA PEDAGOGIA HISTÓRICO-CRÍTICA PARA A EDUCAÇÃO ESPECIAL BRASILEIRA
}

\author{
Régis Henrique dos Reis Silva
} Universidade Federal de Goiás

\section{RESUMO}

Este texto discute sucintamente as contribuições da pedagogia histórico-crítica para a área de educação especial brasileira e também demonstra que a defesa da socialização do conhecimento, por meio da escola, a todas as pessoas, inclusive aos deficientes, está em consonância com a luta de classes em uma perspectiva histórico-filosófica e político-social. Para tanto, primeiramente trataremos dos desafios da educação especial brasileira na contemporaneidade. Na sequência, abordaremos, a partir de alguns apontamentos sobre a pedagogia histórico-crítica e psicologia histórico-cultural, suas contribuições para a educação especial. Por fim, recuperaremos, a partir do exposto, as sínteses e articulações necessárias para demonstrar que a defesa da socialização do conhecimento por meio da escola a todas as pessoas, inclusive aos deficientes, faz parte da luta de classes, particularmente a que se realiza no âmbito educacional.

Palavras-chave: Educação Especial; Pedagogia Histórico-Crítica; Psicologia HistóricoCultural.

\section{CONTRIBUTIONS FROM THE HISTORICAL AND CRITICAL PEDAGOGY FOR SPECIAL EDUCATION BRAZILIAN}

\begin{abstract}
This article discusses briefly the contributions of historical-critical pedagogy to the area of special education in Brazil and also demonstrates that the defense of knowledge socialization through of the school, to all people, including the disabled, is in line with the struggle class in a historical-philosophical and socio-political. To do so, first we will deal of the challenges of special education in contemporary Brazil. In the wakewe will discuss, from some of notes about the historical-critical pedagogy and cultural-historical psychology, his contributions to special education. Finally, we regain, from the above, the syntheses and articulations necessary to demonstrate that the defense of knowledge socialization through school to all people, including the disabled, is part of the class struggle, particularly that takes place in the educational context.

Keywords: Special Education; Historical and Critical Pedagogy; Cultural-Historical Psychology.
\end{abstract}

\section{Desafios da educação especial brasileira na contemporaneidade}

No nosso entendimento e de autores como Frigotto (2001), Saviani e Duarte (2012) e outros, a sociedade capitalista vem sofrendo uma crise profunda, que tem como problemática não mais a produção (material e não material) da riqueza, mas sua apropriação pelas diferentes classes sociais. 
Assim, essa crise tem provocado profundas mudanças no sistema do capital e de seu metabolismo social, nas diferentes esferas sociais, em especial na produtiva, política e ideológica. Por exemplo, na esfera produtiva, os últimos quarenta anos foram de reestruturação e mudanças no mundo do trabalho (ANTUNES, 2009), na economia e na política, a partir do final dos anos 1970, tivemos o avanço da "mundialização do capital" e a ascensão do neoliberalismo como expressão política do modo de gerenciamento do capital capitaneado pela Nova Direita Anglo-saxã (PLATT, 2004), e na esfera ideológica, mais ou menos no mesmo período, mas principalmente depois de 1968, deparamo-nos com um movimento de Recuo da Teoria (MORAES, 2001).

Em virtude do caráter associado-dependente do modo de inserção do Brasil no sistema do capital, as referidas mudanças começaram a ocorrer de forma mais incisiva em nosso país, nos últimos vinte anos, quando a organização social brasileira iniciou um processo de profundas transformações políticas, econômicas e sociais.

Essas transformações ocorreram com maior ênfase a partir dos anos 1990, nos governos de Collor de Melo (1990-1992), Itamar Franco (1992-1994) e Fernando Henrique Cardoso (1995-2002), quando o Brasil iniciou um processo de reforma do estado e da educação, que visava intensificar a internacionalização da economia brasileira face ao processo de reestruturação produtiva e às mudanças no mundo do trabalho.

É oportuno observar que boa parte das reformas realizadas é oriunda das prescrições neoliberais ${ }^{1}$, concretizadas em acordos firmados com agências multilaterais (Banco Mundial, Banco Interamericano de Desenvolvimento, Banco Internacional para Reconstrução e Desenvolvimento, Fundo Monetário Internacional, Organização Mundial do Comércio, Organização das Nações Unidas para a Educação, a Ciência e a Cultura).

Assim sendo, na área educacional brasileira, a reforma realizada visou, entre outras coisas, à universalização da educação básica, principalmente do ensino fundamental, conforme preconizavam as conferências de Educação para Todos (Declaração de Jomtien 1990) e sobre Necessidades Educacionais Especiais (Declaração de Salamanca - 1994), das quais o Brasil foi signatário.

Assim, consubstanciadas em teorias educacionais de base econômica (Teoria do Capital Humano), as declarações de Jomtien e Salamanca preconizavam a educação como elemento do desenvolvimento humano, sob um tom marcadamente "humanista, com enfoque multiculturalista" (DI GIORGI, 1996).

Nesse contexto, nosso interesse por questões pessoais, institucionais e políticosociais voltaram-se para a educação dos deficientes ou, de forma genérica, para a educação especial $^{2}$.

Assim, a partir dos anos 1990, observamos que a educação especial brasileira passou por um processo de redefinição do seu público e da sua organização, pois, embora haja controvérsia sobre as traduções da Declaração de Salamanca, como bem indica Bueno $\left(2008^{3}\right)$, a área, pelo menos no plano da retórica, começou a se orientar pelos princípios inclusivistas ${ }^{4}$.

Entretanto, as controvérsias sobre o modelo inclusivista (educação inclusiva ou inclusão total ${ }^{5}$ ) são oportunas para a observação de que a inclusão escolar de alunos com necessidades educacionais especiais ${ }^{6}$ ganhou destaque nos eventos políticos, científicos e até na própria LDBEN n. 9394/96, a qual dedicou o Capítulo V com três artigos (do 58 ao 60) à educação especial.

Nessa lei, o atendimento aos alunos com necessidades especiais foi definido como dever do estado e que sua educação deveria ser pública, gratuita e preferencialmente na rede regular de ensino. 
Assim, a EEs, que até então estava à parte do sistema educacional comum de ensino, passou a se situar como modalidade da educação escolar, oferecida preferencialmente no ensino regular.

É oportuno observar que, embora a luta pela educação do deficiente no Brasil tenha ganhado impulso com o movimento da Educação Inclusiva, essa luta tem registros de longa data na historiografia da educação brasileira.

Nesse sentido, a partir das considerações dos autores consultados e no levantamento realizado, foi possível identificar e caracterizar três fases (ou períodos) a respeito da constituição da área de EEs no Brasil, que apresentamos na sequência uma breve síntese de cada uma delas ${ }^{7}$.

1. Primeiras iniciativas da educação do deficiente no Brasil: tentativas de institucionalização (Século XVI a 1930): A primeira fase da educação do deficiente no Brasil compreende o período do século XVI a 1930 e caracteriza-se pelas primeiras iniciativas de encaminhamento da questão, com algumas tentativas de institucionalização. Nestas, a concretização da prática pedagógica foi fundamentada nos conhecimentos oriundos das áreas de medicina e psicologia, com maior destaque para primeira (JANNUZZI, 2006).

2. Maior participação da sociedade civil e política na educação do deficiente: tentativas de escolarização (1930-1973): A segunda fase da educação do deficiente no Brasil compreende o período de 1930 a 1973 e caracteriza-se pela maior participação da sociedade civil e política, com algumas tentativas de escolarização, principalmente em instituições especializadas de caráter filantrópico. Nessas instituições, a concretização da prática pedagógica mantém suas bases nos conhecimentos oriundos da área de medicina (vertente médico-pedagógica), mas vai sendo substituída pela psicologia (vertente psicopedagógica) (JANNUZZI, 2006).

3. As políticas sociais de equidade: os princípios integracionistas e inclusivistas nas políticas educacionais do estado gestor (1973-20..): A terceira fase da educação do deficiente no Brasil compreende o período de 1973 aos dias atuais e caracteriza-se pela institucionalização da EEs no país com a criação de órgãos normativos em âmbito federal e estadual, bem como pela promoção de políticas sociais de equidade por parte desses organismos. Essas políticas sociais, consubstanciadas nos princípios integracionistas ${ }^{8}$ e inclusivistas, foram responsáveis pela "[...] instalação de um verdadeiro subsistema educacional, com a proliferação de instituições públicas e privadas de atendimento ao excepcional [...]" (BUENO, 1993, p. 37). Com isso, as bases científicas da prática pedagógica e acadêmica da área se diversificaram e o debate a respeito do modelo de inclusão escolar do aluno deficiente (integração, educação inclusiva e inclusão total) muitas vezes prevaleceu sobre o da necessidade de construirmos uma escola brasileira pública, gratuita, democrática, laica e de qualidade social para todos, inclusive para a população alvo da educação especial.

Situando o debate nos fatos e acontecimentos mais recentes, os aspectos históricos da terceira fase da EEs brasileira evidenciam que, nos últimos 30 anos, a política de "integração escolar" provocou a expansão das classes especiais na escola pública, mas ao mesmo tempo favoreceu o processo de exclusão na escola regular. Já nos últimos 15 anos (aproximadamente), as classes especiais e as escolas especiais privadas e filantrópicas vêm sendo substituídas pelas salas de recursos (atual sala de atendimento educacional especializado), porém de modo precário, visto que boa parte dos alunos com necessidades 
especiais, inserida nas salas de aula da escola regular, está sem receber nenhum tipo de suporte para a escolarização. E isso produziu o fenômeno que Freitas (2002) intitulou de "inclusão-excludente" para se referir à lógica perversa escondida nas políticas de universalização da educação básica, que recorrem à progressão continuada e aos ciclos de escolarização.

Desse modo, autores consubstanciados nos teóricos marxistas, no materialismo histórico-dialético, e empenhados no desenvolvimento de suas análises da apreensão da educação como parte da organização social (educação como mediação) vêm contribuindo para a compreensão da problemática educacional das pessoas com necessidades especiais, principalmente para a lógica das políticas de equidade social.

Nesse sentido, os estudos de Lancilotti (2003), Oliveira (2003), Garcia (2004), Platt (2004), Kassar (2011), entre outros, revelam que os princípios da economia da educação estão na base das políticas equitativas, as quais, baseadas nos princípios integracionistas e inclusivistas, "camuflam-se" de retórica democrática. Isso porque esses princípios fazem parte do movimento de Educação para Todos, que, apoiados em teorias educacionais de bases econômicas (Teoria do Capital Humano), visam ao desenvolvimento humano, enquanto ideologia, como recurso necessário para o desenvolvimento econômico.

Assim sendo, esse movimento não almeja equacionar as desigualdades sociais (diferença substantiva), mas, por meio de políticas sociais compensatórias, minimizá-las para a constituição de uma coesão social (PLATT, 2004; VILARINHO NETO, 2011), constituindo o que a literatura vem intitulando de "formação de uma cultura comum", conforme a execução de uma "agenda globalmente estruturada" (DRAIBE; RIESCO, 2006 apud KASSAR, 2011).

Portanto, trata-se, segundo Sanfelice (2006), de uma política compensatória dentre outras avaliadas por indicadores quantitativos mais do que qualitativos.

No caso do Brasil, essas políticas começaram a ser implantadas nos anos 1990, nos governos Collor de Melo (1990-1992), Itamar Franco (1992-1994) e Fernando Henrique Cardoso (1995-2002), com a reforma do estado e da educação. Não obstante, foi a partir dos anos 2000, no governo Lula, que essas políticas foram potencializadas com a implantação de políticas sociais via gestão por editais, como estratégia de indução do modelo educacional assumido pelo governo, principalmente na área de educação especial.

Como afirmam Garcia e Michels (2011, p. 115):

\begin{abstract}
A organização da política de Educação Especial nos últimos anos pode ser caracterizada como uma "política de resultados", ou seja, um privilegiamento de efeitos que mostrem vantagens na relação custo/benefício tais como maior número de alunos matriculados na relação com os investimentos financeiros. Tais resultados são constitutivos de uma gestão gerencial articulada à racionalização das atividades estatais e que não se atém a uma análise mais qualitativa da educação. Essa concepção de gestão implica uma tentativa de imposição do próprio processo de implantação da política quando define quais são as tarefas locais e como devem ser desenvolvidas.
\end{abstract}

Assim, apesar desses problemas e dificuldades, estamos diante de um movimento contraditório, visto que uma "agenda globalmente estruturada" concilia interesses do estado neoliberal com as reivindicações dos movimentos sociais de e para deficientes ${ }^{10}$. E, neste caso, a contradição é latente, porque, ao mesmo tempo em que se trata de uma ideologia importada de países do centro do capital com sérios prejuízos para a maior parte 
da população brasileira, pois não contempla mudanças estruturais na sociedade, não podemos negar que essas políticas vêm alterando a relação da educação regular com a educação especial, ou pelo menos minimizando o distanciamento que havia entre elas. Também, do lado da educação especial, elas vêm se aproximando dos problemas e movimentos sociais de luta da educação regular, particularmente a defesa pela escola pública, laica, gratuita e de qualidade para todos.

Assim sendo, essas políticas, diante das contradições existentes na dinâmica social mais ampla e das contradições da realidade educacional em particular, podem, quem sabe, vir a se constituir como uma estratégia de superação dos problemas educacionais brasileiros. Pois essas políticas, conforme a perspectiva assumida para debatê-las e a teoria pedagógica para desenvolvê-las, podem possibilitar aos educadores e à sociedade em geral ir "à raiz" dos problemas sociais e educacionais, favorecendo a compreensão histórica das diferenças e dos mecanismos explícitos e implícitos de exclusão educacional e social como elementos justificadores das desigualdades sociais, em especial da acumulação privada dos meios de produção e da exploração do homem pelo homem.

Além disso, uma escola pública, laica, gratuita e de qualidade para todos, inclusive para as pessoas com deficiência e/ou necessidades especiais, não poderá surgir enquanto existirem mecanismos tão efetivos de exclusão e seletividade social, como os praticados pela escola brasileira.

Após essas considerações gerais sobre a educação do deficiente e da educação especial brasileira, discutiremos, no próximo tópico, as contribuições que a pedagogia histórico-crítica, enquanto formulação coletiva que está em construção, pode oferecer à educação especial brasileira, principalmente por meio da sua aproximação com a psicologia histórico-cultural.

\section{Alguns apontamentos sobre a pedagogia histórico-crítica e a psicologia histórico-cultural}

Segundo Duarte e Saviani (2012), boa parte das ideias hegemônicas na educação em tempos recentes centra-se na crítica à "metafísica do sujeito", particularmente a crítica à razão, à consciência, à verdade e à objetividade do conhecimento. Os referidos autores intitulam esse movimento de neopragmatismo, o qual, no esforço de se opor à referida metafísica, torna-se ele próprio fortemente metafísico, reduzindo tudo à linguagem. Como contraponto a esse movimento, Duarte e Saviani (2012) apresentam a perspectiva histórico-ontológica da formação humana (radicalmente antimetafísica), particularmente o pensamento de Marx e sua filosofia historicizada contida nos Manuscritos Econômicofilosóficos, de 1844.

Pois é justamente a partir dos esforços de construção de uma pedagogia concreta (pedagogia histórico-crítica) de inspiração marxiana e marxista, os quais foram realizados inicialmente por Saviani, há pouco mais de 30 anos, que um coletivo de professores e pesquisadores passou a se empenhar na apreensão dos elementos fundantes do materialismo histórico-dialético, tanto nos aspectos ontológicos como epistemológicos e metodológicos, passando assim a contribuir para o desenvolvimento da referida pedagogia.

Conforme Duarte (2012), a partir da análise de trechos da obra de Saviani, é possível identificar elementos que podem contribuir para uma ontologia da educação, dentre elas as definições de ato educativo e trabalho educativo. Nestas são evidenciadas as características basilares das obras de Saviani, quais sejam: a busca pela superação da dualidade entre essência e historicidade; e o seu esforço de que uma teoria marxista da educação possa ser também uma pedagogia marxista. 
Desse modo, iniciamos nossos apontamentos sobre a pedagogia histórico-crítica com a recuperação da natureza e a especificidade da educação, a partir do conceito de trabalho educativo desenvolvido por Saviani (2008):

[...] a natureza humana não é dada ao homem, mas é por ele produzida sobre a base da natureza biofísica. Consequentemente, o trabalho educativo é $\mathrm{o}$ ato de produzir, direta e intencionalmente, em cada indivíduo singular, a humanidade que é produzida histórica e coletivamente pelo conjunto dos homens. Assim, o objeto da educação diz respeito, de um lado, à identificação dos elementos culturais que precisam ser assimilados pelos indivíduos da espécie humana para que eles se tornem humanos e, de outro lado e concomitantemente, à descoberta das formas mais adequadas para atingir esse objetivo (SAVIANI, 2008, p. 13).

Observem que, para Saviani (2008), um problema central para a educação, o qual constituirá em seu objeto de estudo, é a identificação do quê e como ensinar. Logo,

[...] os diferentes tipos de saber não interessam em si mesmos; eles interessam, sim, mas enquanto elementos que os indivíduos da espécie humana necessitam assimilar para que se tornem humanos. Isto porque o homem não se faz homem naturalmente; ele não nasce sabendo ser homem, vale dizer, ele não nasce sabendo sentir, pensar, avaliar, agir. Para saber pensar e sentir; para saber querer, agir ou avaliar é preciso aprender, o que implica trabalho educativo. Assim, o saber que diretamente interessa à educação é aquele que emerge como resultado do processo de aprendizagem, como resultado do trabalho educativo. Entretanto, para chegar a esse resultado, a educação tem que partir, tem que tomar como referência, como matéria-prima de sua atividade, o saber objetivo produzido historicamente (SAVIANI, 2008, p. 7).

Desse modo, um elemento que reforça a noção do trabalho educativo, como natureza e especificidade da educação, conforme apresentado por Saviani (2008), é a possibilidade da sua institucionalização, que foi o que ocorrera com o advento da sociedade moderna, quando o trabalho educativo foi institucionalizado pela escola, que se constituiu como instituição responsável pela socialização do saber sistematizado.

Segundo Saviani (2008, p. 7):

[...] Esta passagem da escola à forma dominante de educação coincide com a etapa histórica em que as relações sociais passaram a prevalecer sobre as naturais, estabelecendo-se o primado do mundo da cultura (o mundo produzido pelo homem) sobre o mundo da natureza. Em consequência, o saber metódico, sistemático, científico, elaborado, passa a predominar sobre o saber espontâneo, "natural", assistemático, resultando daí que a especificidade da educação passa a ser determinada pela forma escolar.

Entretanto, o fato de o saber ser sistematizado não significa dizê-lo que é neutro. Assim sendo, Saviani (2008) pondera que não podemos cair na falácia positivista, que identifica objetividade e neutralidade, pois, embora não exista conhecimento desinteressado, "a objetividade é possível porque não é todo interesse que impede o conhecimento objetivo. Há interesses que não só não impedem como exigem a 
objetividade" (SAVIANI, 2008, p. 8). Por isso, Saviani refere-se ao saber objetivo produzido historicamente.

Então Saviani (2008) afirma que a tarefa a que se propõe a pedagogia históricocrítica em relação à educação escolar implica em:

a) Identificação das formas mais desenvolvidas em que se expressa o saber objetivo produzido historicamente, reconhecendo as condições de sua produção e compreendendo as suas principais manifestações, bem como as tendências atuais de transformação.

b) Conversão do saber objetivo em saber escolar, de modo que se torne assimilável pelos alunos no espaço e tempo escolares.

c) Provimento dos meios necessários para que os alunos não apenas assimilem o saber objetivo enquanto resultado, mas apreendam o processo de sua produção, bem como as tendências de sua transformação (SAVIANI, 2008, p. 9).

Desse modo, considerando a necessidade de definição de um critério para a identificação dos elementos culturais que precisam ser assimilados, Saviani (2008) sugere trabalharmos com a noção de clássico, que

[...] não se confunde com o tradicional e também não se opõe, necessariamente, ao moderno e muito menos ao atual. O Clássico é aquilo que se firmou como fundamental, como essencial. Pode, pois, constituirse num critério útil para a seleção dos conteúdos do trabalho pedagógico (SAVIANI, 2008, p. 14).

A respeito da descoberta das formas adequadas de desenvolvimento do trabalho pedagógico, Saviani observa que esta questão [...] trata-se da organização dos meios (conteúdos, espaço, tempo e procedimentos) através dos quais, progressivamente, cada indivíduo singular realiza, na forma de segunda natureza, a humanidade produzida historicamente (SAVIANI, 2008, p. 14).

Portanto, a partir das elaborações de Saviani (2008), podemos afirmar que, no horizonte da pedagogia histórico-crítica, está a constituição de uma escola que supere a escola tradicional e a escola nova.

Nesse sentido, inclusive, Saviani, ao ponderar sobre os embates entre a escola tradicional e a escola nova, recupera uma transcrição de Gramsci como forma de sinalização de uma perspectiva superadora das referidas escolas:

Deve-se distinguir entre escola criadora e escola ativa, mesmo na forma dada pelo método Dalton. Toda escola unitária é escola ativa, se bem que seja necessário limitar as ideologias libertárias nesse campo [...]. Ainda se está na fase romântica da escola ativa, na qual os elementos da luta contra a escola mecânica e jesuítica se dilataram morbidamente por causa do contraste e da polêmica: é necessário entrar na fase "clássica", racional, encontrando nos fins a atingir a fonte natural para elaborar os métodos e as formas (GRAMSCI, 1968, p. 124 apud SAVIANI, 2008, p. 17-18).

Na transcrição a seguir, Saviani é mais elucidativo ainda. Vejamos então: 
Às vezes me dá a impressão de que, passados mais de cinquenta anos, continuamos ainda na fase romântica. Não entramos na fase clássica. E o que é a fase clássica? [...]

Ora, clássico na escola é a transmissão-assimilação do saber sistematizado. Este é o fim a atingir. É aí que cabe encontrar a fonte natural para elaborar os métodos e as formas de organização do conjunto das atividades da escola, isto é, do currículo. E aqui nós podemos recuperar o conceito abrangente de currículo: organização do conjunto das atividades nucleares distribuídas no espaço e tempo escolares. Um currículo é, pois, uma escola funcionando, quer dizer, uma escola desempenhando a função que lhe é própria.

Vê-se, assim, que para existir a escola não basta a existência do saber sistematizado. É necessário viabilizar as condições de sua transmissão e assimilação. Isso implica dosá-lo e sequenciá-lo de modo que a criança passe gradativamente do seu não domínio ao seu domínio. Ora, o saber dosado e sequenciado para efeitos de sua transmissão-assimilação no espaço escolar, ao longo de um tempo determinado, é o que nós convencionamos chamar de "saber escolar" (SAVIANI, 2008, p. 18).

Em síntese, as contribuições da pedagogia histórico-crítica para a educação especial brasileira estão nos pressupostos filosóficos, na proposta pedagógico-metodológica e no significado político da sua realização, porque, ao se fundamentar em bases marxianas e marxistas, leva à compreensão, sob a valorização da história, da educação e do homem que educa.

É nesse sentido que a pedagogia histórico-crítica e a psicologia histórico-cultural irão se aproximar e contribuir, uma com a outra, para a educação escolar das pessoas com e sem deficiência.

Por isso, não podemos deixar de mencionar a importância da perspectiva assumida por Vygotsky, no que se refere à constituição social do psiquismo e ao papel da mediação para a formação das funções superiores psicológicas.

Como afirma Barroco (2011), os trabalhos desenvolvidos por Vygotsky e por outros psicólogos russos e soviéticos são contribuições marcantes para a educação especial soviética e não soviética, porque enfatiza que todas as pessoas (deficientes e não deficientes) podem ser educadas, face o caráter histórico-cultural de formação de seus psiquismos.

No caso dos deficientes que apresentem algum déficit de origem orgânica (primeira natureza ou de ordem biofísica), como cegueira, surdez, paraplegia etc, segundo Vygotsky, esse déficit não se constitui necessariamente como um fator limitador do desenvolvimento, mas o seria, sim, as condições sócio-históricas.

Como afirma Vygotsky e Luria (1996 apud BARROCO, 2011, p. 173),

[...] as pessoas com deficiência, mesmo tendo grandes especificidades em seus desenvolvimentos, podem e devem frequentar a escola, e o que esta lhes ensina deve projetá-las a outro patamar, deve transformá-las, metamorfoseá-las, deve contribuir para que passem de crisálidas a borboletas [...]. Essa seria, pois, a escola que poderíamos chamar de inclusiva.

Assim sendo, concordamos com Barroco (2011) quanto à necessidade de que a formação de psicólogos e de educadores valorize a história e a filosofia, particularmente os conteúdos clássicos dessas áreas, no intuito de que a prática profissional e pedagógica 
deles supere os treinos sensoriais e assuma uma perspectiva mais ampla de desenvolvimento humano.

Acreditamos que essa perspectiva inspirará outra proposta de educação especial, a qual ganhará materialidade com as defesas marxistas de educação escolar contempladas na pedagogia histórico-crítica, assim como coincidirá com as noções de homem, educação e sociedade presentes na referida pedagogia e na psicologia histórico-cultural.

\section{Pedagogia histórico-crítica e educação especial na luta de classes da educação escolar brasileira}

A contribuição da pedagogia histórico-crítica está nos pressupostos filosóficos, na proposta pedagógico-metodológica e no significado político da sua realização, pois, como dissemos anteriormente, na esfera ideológica temos vivenciado um processo de Recuo da Teoria (MORAES, 2001). Nesse processo, diversas teorias vêm propagandeando o caos, a impossibilidade de apreensão da realidade, formulando uma tendência teórica de ceticismo epistemológico e relativismo ontológico de diferentes níveis, cujo resultado praxiológico tem sido a aceitação e/ou conformação de um quadro social conservador, em que, no limite, as mudanças sociais possíveis são conjunturais e orientadas por uma lógica pragmática e individualista.

Portanto, como não concordamos com essa visão, aproximamo-nos das perspectivas teóricas que afirmam a inteligibilidade do real (a realidade existe e é possível apreendê-la) e a sua superação em termos estruturais.

Assim, no campo particular da educação, encontramos a pedagogia históricocrítica, que, além de não aderir ao ceticismo epistemológico e relativismo ontológico, assim como a psicologia histórico-cultural, defende a apropriação da cultura por meio do ensino sistematizado e a transmissão de conhecimentos clássicos como função precípua da Escola. Ao mesmo tempo, visualiza nesta a possibilidade de se constituir um lócus de compreensão da marginalização, inclusive dos deficientes - suas origens, desdobramentos e os mecanismos para seu enfrentamento. Sendo assim, as duas teorias sinalizam para a possibilidade de uma práxis transformadora a partir da escola.

Conforme Duarte e Saviani (2012), há uma contradição que marca a história da educação escolar na sociedade capitalista.

[...] Trata-se da contradição entre a especificidade do trabalho educativo na escola - que consiste na socialização do conhecimento em suas formas mais desenvolvidas - e o fato de que o conhecimento é parte constitutiva dos meios de produção que, nesta sociedade, são propriedade do capital e, portanto, não podem ser socializados (SAVIANI; DUARTE, 2012, p. 2).

Assim, segundo os autores, a referida contradição, por ser dinâmica, pode produzir movimento pelo menos em duas direções: uma conforme os interesses da classe dominante, representada pela precarização da escola pública, e outra, de acordo com os interesses da classe trabalhadora, representada pela realização da função precípua da escola, qual seja a socialização do conhecimento como eixo central de todas as atividades realizadas no seu interior.

Portanto, os autores ponderam que a luta pela realização da função precípua da escola pública, "[...] por si mesma, não revolucionará a sociedade pelo simples fato de que a escola não tem o poder de mudar a sociedade" (SAVIANI; DUARTE, 2012, p. 4). Porém, a efetivação da revolução como transformação consciente da realidade social atual por uma nova forma de regulação das relações sociais de modo superior, em outras 
palavras, qualitativamente superior ao modo de regulação vigente, é uma tarefa complexa e altamente desenvolvida no que se refere ao processo criativo, o qual não se faz sem a apropriação do que existe de melhor no patrimônio cultural da humanidade. Por isso, a defesa da escola pública como lócus privilegiado de transmissão-assimilação do conhecimento historicamente produzido pelo Ser Humano coincide com a luta pelo socialismo, inclusive com a luta pelos direitos sociais dos deficientes (tratando-se, neste caso, de superação por incorporação).

\section{REFERÊNCIAS}

ANTUNES, R. Os sentidos do Trabalho: ensaio sobre a afirmação e a negação do trabalho. 2. ed. São Paulo, SP: Boitempo, 2009. 287 p. (Coleção Mundo do Trabalho)

BARROCO, S. M. S. Pedagogia histórico-crítica, psicologia histórico-cultural e educação especial: em defesa do desenvolvimento da pessoa com e sem deficiência. In: MARSIGLIA, A. C. G. (Org.). Pedagogia histórico-crítica: 30 anos. Campinas, SP: Autores Associados, 2011. (Coleção Memória da Educação)

BUENO, J. G. S. A pesquisa educacional e a transformação das práticas escolares. In: DECHICHI, C; SILVA, L. C. da. (Orgs.) Inclusão escolar e educação especial: teoria e prática na diversidade. Uberlândia: EDUFU, 2008. p. 65-80.

BUENO, J. G. S. Educação Especial brasileira: integração/segregação do aluno diferente. São Paulo: EDUC, 1993.

DI GIORGI, C. A. G. Concepções do Banco Mundial e outros organismos internacionais sobre educação: problemas e contradições. Revista Nuances - v. II - out. 1996. Unicamp, SP.

DORÉ, R. et al. A integração escolar: os principais conceitos, os desafios e os fatores de sucesso no secundário. In: MANTOAN, M. T. E. et al. A Integração de pessoas com deficiência: contribuições para uma reflexão sobre o tema. São Paulo: Menom/SENAC, 1998. p. 174-183.

DUARTE, N. Lukács e Saviani: a ontologia do ser social e a pedagogia histórico-crítica. In: SAVIANI, D; DUARTE, N. Pedagogia histórico-crítica e luta de classes na educação escolar. Campinas, SP: Autores Associados, 2012.

FREITAS, L. C. de. A internalização da exclusão. Educação e Sociedade. Campinas, v. 23, n. 80, set. 2002. p. 299-325.

FRIGOTTO, G. A nova e as velhas faces da crise do capital e o labirinto dos referenciais Teóricos. In: FRIGOTTO, G; CIAVATTA, M. (Orgs.). Teoria e Educação no Labirinto do Capital. 2. ed. Petrópolis, RJ: Vozes, 2001.

GARCIA, R. M. C; MICHELS, M. H. A política de educação especial no Brasil (19912011): uma análise da produção do GT 15 - educação especial da ANPED. Rev. Bras. Ed. Esp., Marília, v.17, Maio-Ago. 2011. Edição Especial. p. 105-123.

GARCIA. R. M. C. Políticas públicas de inclusão: uma análise no campo da educação especial brasileira. 2004. Tese (Doutorado em Educação). UFSC. Florianópolis, 2004.

JANNUZZI, G, S de M. A educação do deficiente no Brasil: dos primórdios ao início do século XXI. 2. ed. Campinas, SP: Autores Associados, 2006. 243 p. 
KASSAR, M. de C. M. Percursos da constituição de uma política brasileira de educação especial inclusiva. Rev. Bras. Ed. Esp. Marília, v.17, Maio-Ago., 2011. Edição Especial. p. 41-58.

LANCILLOTTI, S. S. P. Deficiência e trabalho: redimensionando o singular no contexto universal. Campinas, SP: Autores Associados, 2003. (Coleção Polêmicas do Nosso Tempo, 85). $111 \mathrm{p}$.

MENDES, E. G. A radicalização do debate sobre inclusão escolar no Brasil. Rev. Bras. Educ., Campinas: Autores Associados, v. 11, n. 33, set./dez., 2006. p. 387-405.

MENDES, E. G. Breve histórico da educação especial no Brasil. Revista Educación y Pedagogía, Medellín, Universidad de Antioquia, Facultad de Educación, vol. 22, n. 57, mayo-agosto, 2010. p. 93-109.

MORAES, M. C. M. de. Recuo da teoria: dilemas na pesquisa em educação. Revista Portuguesa de Educação. Vol.14(1), p.7-25, Universidade do Minho, 2001.

VILARINHO NETO, S. Equidade: apontamentos para a educação do corpo. Revista Brasileira de Ciências do Esporte, Florianópolis, v. 33, n. 1, jan./mar. 2011. p. 135-148.

OLIVEIRA, C. B. de. Políticas educacionais inclusivas para a criança deficiente: concepções e veiculações no Colégio Brasileiro de Ciências do Esporte, 1978-1999. 2003. Dissertação (Mestrado em Educação Física) - Faculdade de Educação Física, Unicamp, Campinas/SP, 2003.

PLATT, A. D. O paradigma inclusivo das políticas educacionais e o paradigma excludente das políticas econômicas nos anos 90: o constructo sócio conceitual da normalidade/anormalidade (ou adequação social). Tese (Doutorado em Educação). Unicamp. Campinas, SP, 2004.

SANFELICE, J. L. Inclusão educacional no Brasil: limites e possibilidades. Revista de Educação/PUC-Campinas. Campinas, n. 21, nov. 2006. p. 29-40.

SAVIANI, D; DUARTE, N. Pedagogia histórico-crítica e luta de classes na educação escolar. Campinas, SP: Autores Associados, 2012.

SAVIANI, D. Pedagogia histórico-crítica: primeiras aproximações. 10. ed. rev. Campinas, SP: Autores Associados, 2008. (Coleção Educação Contemporânea)

VIDAL, M. H. C. V. Atando nós que constroem redes... A expansão da rede Pitágoras no contexto da transnacionalização da educação. 2006. 159 f. Dissertação. (Mestrado em Educação). Universidade Federal de Uberlândia, Uberlândia, 2006.

\footnotetext{
${ }^{1}$ Este termo refere-se a uma série de prescrições elaboradas, a partir do Consenso de Washington, que ocorreu em meados dos anos 1980, onde os países do centro do capital definiram o futuro da economia mundial, as políticas de desenvolvimento e especificamente o papel do estado (VIDAL, 2006).

${ }^{2}$ Conforme Bueno (1993, p. 37), até os anos 1950, no Brasil, "praticamente não se falava em educação especial, mas na educação de deficientes". Entretanto, o termo Educação Especial, ou sua abreviatura "EEs", é genericamente empregado.

${ }^{3}$ Segundo o autor, a primeira tradução impressa da Declaração de Salamanca, publicada pela Coordenadoria Nacional para Integração da Pessoa Portadora de Deficiência - CORDE, em 1994, assumia uma orientação integradora. Já em 2007, essa mesma coordenadoria altera essa tradução com a substituição de integração por inclusão, o que gera um dilema conceitual e de fundamentação política (BUENO, 2008).
} 
${ }^{4}$ Segundo Stainback e Stainback (apud DORÉ et al.,1997, p. 176), “[...] trata-se de um novo paradigma [...] a noção de 'full inclusion' prescreve a educação de todos os alunos nas classes e escolas de bairro [...] reflete mais clara e precisamente o que é adequado: todas as crianças devem ser incluídas na vida social e educacional da escola e classe de seu bairro, e não somente colocada no curso geral ('mainstream') da escola e da vida comunitária, depois de ele já ter sido excluído".

${ }^{5}$ Ver Mendes (2006).

${ }^{6}$ Termo utilizado para se referir não só às pessoas com deficiência, mas a todas as pessoas "excluídas" da escola e da sociedade, como os negros, os índios, as mulheres, os pobres e as demais minorias sociais (MENDES, 2006).

${ }^{7}$ Sobre essas fases, é importante destacarmos que os marcos cronológicos utilizados para sua elaboração não são "camisas de força" e muito menos unânimes, mas, sim, um modo aqui estabelecido para tratar as temáticas. No caso das fases da EEs brasileira, articulamos o esquema de organização do processo de criação e desenvolvimento da Educação do Deficiente no Brasil elaborado por Jannuzzi (2006) com a discussão das políticas de EEs na perspectiva da Educação Inclusiva desenvolvida pelo Governo brasileiro na transição dos anos 1990 para os anos 2000.

${ }^{8}$ Normalização/integração e mainstreaming - Princípio evocado no Brasil, em fins dos anos 1970 e início dos anos 1980, cuja proposta básica consistia em oferecer ao excepcional as condições de vida idênticas às de outras pessoas, e assim minimizar as diferenças e potencializar as semelhanças, reconhecendo nos excepcionais as suas potencialidades. Por isso, há a ênfase no discurso da integração (mainstreaming), pois o princípio da normalização demandava a necessidade de integração progressiva do excepcional com os considerados normais, inclusive no processo de escolarização, o que requeria aproximação política, administrativa e pedagógica entre os ensinos regular e especial (JANNUZZI, 2006, p.180-181).

9 Agenda da ONU para o combate à discriminação dos deficientes - 1981: Ano Internacional da Pessoa Deficiente; 1982: Programa de Ação Mundial para as Pessoas Deficientes (PAM); 1983 a 1992: Década das Pessoas Deficientes.

${ }^{10}$ Em 1980, ocorreu o I Encontro Nacional de Entidades de Pessoas Deficientes, a partir do qual se consolidaram várias entidades representativas das categorias de pessoas com deficiências (MENDES, 2010), assim como, no ano de 1981, foi promovido pela ONU o "Ano Internacional das Pessoas Deficientes" (AIPD). Segundo Jannuzzi (2006), esse evento sintetizou o espírito da luta das pessoas com deficiência e contribuiu para solidificar a participação dessa população na discussão de seus próprios problemas. Por isso, o trocadilho das palavras de e para ao nos referirmos aos movimentos sociais dos deficientes, pois cada vez mais foram constituindo movimentos sociais de deficientes (fundadas e dirigidas por deficientes) e não só para deficientes (geralmente fundadas e dirigidas por pessoas não deficientes).

Recebido: $\quad$ set-13

Aprovado: $\quad$ set-14 